\title{
The influence of the ageing-fatigue degradation on the mechanical properties of glass-reinforced composites
}

\author{
Małgorzata Szymiczek*, Maciej Rojek, Gabriel Wróbel \\ Silesian University Technology in Gliwice, Department of Theoretical and Applied Mechanics \\ "Corresponding author: e-mail: malgorzata.szymiczek@polsl.pl
}

\begin{abstract}
Drawing up diagnostic relations between thermal characteristics determined in thermal imaging examinations and mechanical properties, allowing for forecasting the state of material during the use, was a purpose of the work. Research was performed on polyester - glass composites which were subjected to the ageing-fatigue degradation process in a device created specifically for that purpose. It was indicated how to assess the degree of the decline, taking into account the fall in material strength properties. The basis of a method was measurement of changes in temperature in activated thermal processes. Relations between changes of the speed of heating and cooling were related to the bending strength and the modulus of elasticity. Diagnoses were backed up with microscopic examinations.
\end{abstract}

Keywords: glass-polyester composites, thermal and mechanical properties, thermovision.

\section{INTRODUCTION}

Polymer composites are currently applied successfully on the responsible constructions in aviation, automotive or chemical industry. Open and not entirely explored problem is the number of non-destructive diagnostics methods aimed at the assessment concerning the loss degree of strength properties during their exploitation. Contemporarily, many scientific research centres connected with aviation or car industry (pressure hydrogen tanks) deal with the problem. The defects that occur at the stage of composite production, such as air bladders or bad supersaturarion of the reinforcement might be unequivocally identified and the diagnostic procedures have been known for years. The results of the research presented in the literature of the subject refer to identification procedure of the defects that also occur during the exploitation. These are however, the defects in the dimension of macro-discontinuities or delamination ${ }^{\mathbf{1 - 1 1}}$.

Within the work, we took issue with the problem of identification and continuous monitoring of the construction starting from the phase of production, assembling and exploitation, up to the elimination of the elements in which occur the areas with defects in macro size that lead to delamination.

The diagnostics of the system is possible thanks to non-destructive research methods such as termovision, ultrasonic defectoscopy and the like $\mathrm{8}^{\mathbf{1 2}-14}$. Establishing the diagnostic relations on the basis of thermal characteristics, or the transition time of a ultrasonic wave in relation to the strength properties is rather unknown but it allows the elimination of construction elements which endanger the further and safe exploitation.

The defects appearing in the microscopic size which lead to the loss of the load-bearing properties result from progressive material degradation process, which in turn is the effect of environmental impact and the load of the system. The initiating factors which accompany the degradation might be physical interactions (stresses, heat, high energy radiation) as well as the chemical ones (oxygen, aggressive media) ${ }^{\mathbf{1 5}, \mathbf{1 7}}$. Most often degradation processes are of the synergetic character and result in interactions between the individual stimuli. Such degrada- tion course appears, in most of instances, in application of thermosetting materials and their composites, e.g.: the influence of heat causes acceleration of the fatigue degradation, internal stresses intensify thermal degradation, aggressive environment influences the acceleration of thermal degradation of the composite fatigue. In practice we encounter much more complicated systems degradation factors. For example, the impact of cyclically variable loads on the composite ${ }^{15,18}$ leads to irreversible thermo kinetic processes. The failure mechanism of such a material is complex, it may occur as a result of the cracking of the matrix and fiber, decohesion and delamination. The fatigue process causes the gradual degradation of the composite structure, which manifests itself in the form of the reduction of stiffness. The failure mechanisms of polymer construction composites depend on the position of reinforcement ${ }^{\mathbf{1 9}}$. In case of laminate, the destruction process occurs in stages, from microcracks of the matrix to interfacial delamination, which in consequence might lead to delamination.

A particularly interesting diagnostic problem is the filament wound constructions of glass or carbon fibres with the polymer matrix. These are most often containers and pipes for storing and transportation of the materials which are environmentally dangerous ${ }^{20}$. Within the work we established of the diagnostic relations concerning cylindrical axially symmetric shells which connect the thermal characteristics with the strength properties of the material.

The purpose of the work was development relationship between the loss of load-bearing properties of glass-polyester and thermal characteristics with the application of the active pulsed thermography method. This required conducting the fatigue-ageing researches, which are the degradation tool. The flexural strength and thermal characteristics allow the assessment of the composite material state. 


\section{EXPERIMENTAL}

\section{Material}

As the subject of the research we used the pipe samples with the diameter of $152 \mathrm{~mm}$ and the length of $630 \mathrm{~mm}$, made of polyester resin reinforced glass fibres type $\mathrm{E}$ (with the weight share of glass 52\%). The examination of the composite shell $8 \mathrm{~mm}$ of thickness was conducted with the use of the method of glass fibre cross winding with three glass mat interlayers with weight of $350 \mathrm{~g} / \mathrm{m}^{2}$. Glass roving was cross wound in layers at the angle of $54^{\circ}$. The whole of the coating was protected with the mat, grammage of $130 \mathrm{~g} / \mathrm{m}^{2}$. At the ends of the pipes, the flanges were circumferentially wound, which ensured the proper stiffness in the sealing points during the pressure examination. In order to stabilize the properties, all the tested pipes were subjected to curing in the heat chamber with the forced air circulation in the temperature of $60^{\circ}$ for $24 \mathrm{~h}$.

Some of the samples subjected to examination had defects which occurred at the stage of production. These were the defects at the macro level, like bladders, uneven distribution of fibres or broken and braided fibres (Fig. 1), which were identified on the basis of scanning with the thermal imaging camera. Such samples were eliminated from the further research. In order that diagnose the changes in the condition of composite material, on each of the samples and mesh of measurement points was marked -4 for 4 forming the cylindrical surface of the roller (plotted at $90^{\circ}$ ).

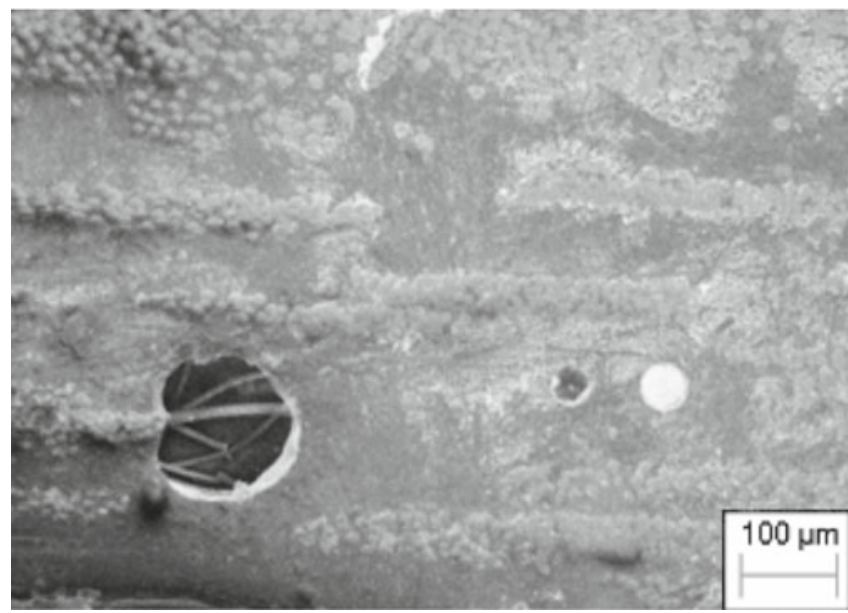

Figure 1. Microscopic view of defects in the composite sample eliminated from the research

In the next stage, the samples were cut out of the composite cylindrical shells for the destructive research i.e. concerning flexural strength, and thermal diffusion. These samples were subjected to conditioning in the temperature of $60^{\circ} \mathrm{C}$ for $24 \mathrm{~h}$.

\section{Testing}

The experimental part of the work embraced the fatigue-ageing examination, thermal characteristics of thermovision method, flexural strength, and microscopic - SEM.

The research of the degradation process was conducted on the device equipped with the two-stage hydraulic system (oil and water) - Figure 2a. First degree of the hydraulic system (oil) was supposed to generate constant pressure, powering individual hydraulic intensifiers, from which water in the second degree of the system loaded the given research sample. Water pressure was subject to regulation. Test stand gave a possibility to simultaneously examine 5 samples with independent cycles of the load and register parameters of the load (pressure) changes. Additionally, the device in the lower part of the chamber was equipped with the system of immersion thermostat heaters which allowed to maintain the same temperature of the bath in which samples were plun$\operatorname{ged}^{21-22}$. Research was conducted in the temperature of $30^{\circ} \mathrm{C}$, with rectangular forcing into load the arrangement to the maximum pressure (7 MPa i $10 \mathrm{MPa}$ ), where the time of pressure growth was $1.5 \mathrm{~s}$, with the loading time with maximum pressure of $2 \mathrm{~s}$ in an aqueous medium.

The scheme of pipe samples deformation is shown in Figure 2b.

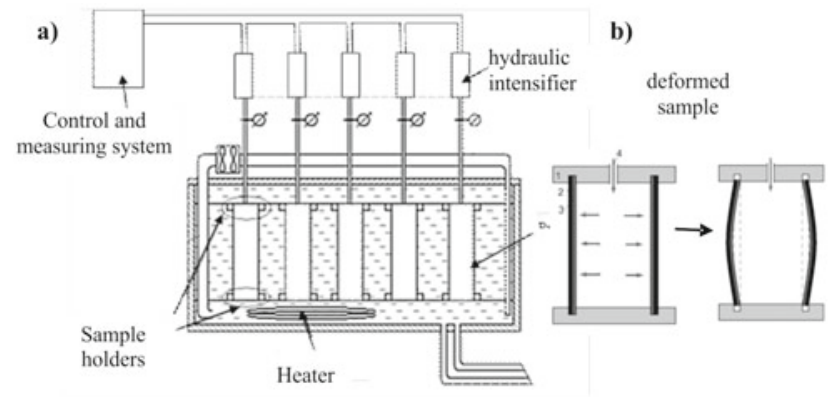

Figure 2. The scheme of the working station (a) and deformation of pipe sample under the internal pressure (b)

The researched samples were subjected to the continuous diagnosing of the material condition by non-destructive thermovisual method in the marked measurement points, the strength characteristic and thermal diffusivity established in accordance with the program assumed, in compliance with Table 1 . Before starting the fatigueageing examination, all the pipes were scanned with the use of thermal imaging camera at the working station presented in Figure 3.

The registration of the changes in temperature was conducted with the use of camera FLIR A-615, supported by software IRControl. The camera was set in the distance of $1000 \mathrm{~mm}$ from the pipe examined, with the halogen lamp in the distance of $450 \mathrm{~mm}$. The sample heating time was $60 \mathrm{~s}$. Thermovision registration, which embraced both the heating chase and the cooling chase, was conducted at the period of $120 \mathrm{~s}$. In the IRControl program, the areas corresponding to measurement points, in which the changes in temperature were registered, were marked.

Figure 4 shows the exemplary course of changes concerning the changes in temperature in the given point on the surface of the examined glass-polyester pipe, in the

Table 1. Program of properties examination

\begin{tabular}{|l|c|c|c|c|c|c|c|c|c|c|c|}
\hline $\begin{array}{l}\text { No } \\
\text { of examination }\end{array}$ & 1 & 2 & 3 & 4 & 5 & 6 & 7 & 8 & 9 & 10 & 11 \\
\hline Number of cycles $10^{3}$ & 5 & 10 & 20 & 40 & 50 & 60 & 80 & 100 & 110 & 120 & 150 \\
\hline
\end{tabular}




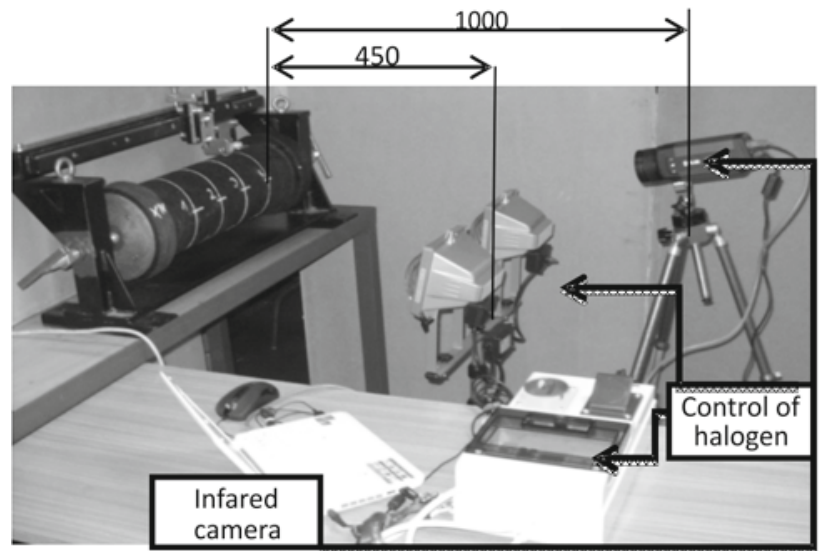

Figure 3. The view of the working station for the thermal imaging diagnostics research

specified phase of the fatigue-ageing process. For the diagnostic purpose the characteristic maximum temperature $\mathrm{T}_{\max }$ (registered after $60 \mathrm{~s}$ ) was chosen. It was referred to the initial temperature $\left(T_{p}\right)$ and the one after $80 \mathrm{~s}$ since the beginning of the heating process $\left(T_{c}\right.$. It should be emphasized, that the values have the local character and might be, in case of inhomogeneous material, only make the basis for the local assessment of its condition. For the needs of the larger area material the analysis of diagnostics values distribution in this area is necessary. Thermal imaging technique gives the possibility of such widening of the research program.

On the basis of presented process of temperature changing in time (Fig. 5) the average heating rate was established. It is expressed by the formula:

$v_{n}=\frac{T_{\max }-T_{p}}{t_{\max }}$

where: $\mathrm{T}_{\max }-$ maximum heating temperature, $\mathrm{T}_{\mathrm{p}}-$ initial temperature, $\mathrm{t}_{\max }$ - time of heating to the maximum temperature.

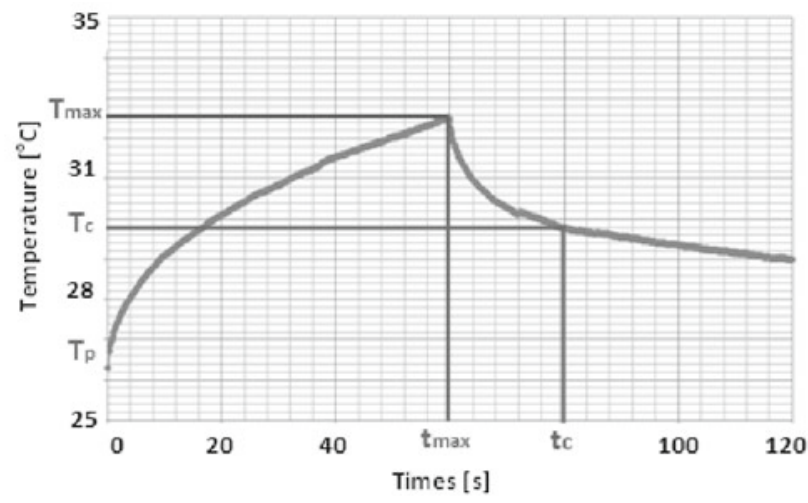

Figure 4. Exemplary relation between the temperature and registration times in the selected point on the surface of the pipe sample with the characteristic properties marked

The average cooling rate was expressed by the formula:

$V_{h}=\frac{T_{\max }-T_{c}}{t_{c}}$

where: $\mathrm{T}_{\mathrm{c}}$ - cooling temperature determined after time $80 \pm 0.5 \mathrm{~s}, \mathrm{t}_{\mathrm{c}}-$ cooling time determined from the relation:

$t_{c}=(80 \pm 0.5 \mathrm{~s})-t_{\max }$
Additionally, we conducted the thermovisual examination of flat samples, cut out from the middle area of degraded glass-polyester pipes. The tests were performed at the working station designed and performer in compliance with the norm PN-EN 821-2:200223 which refers to the measurements of thermal diffusivity in the non-determined state, in the frame of the project N501 $02932 / 2474^{24}$. The principle of station's working is presented in Figure 5.

The changes in temperature were carried out on the other side of thermal activation (so called transition method) using the instrumentation and the software as in previously. The samples were heated for $12 \mathrm{~s}$, the change of temperature was registered for $180 \mathrm{~s}-$ Figure 6.

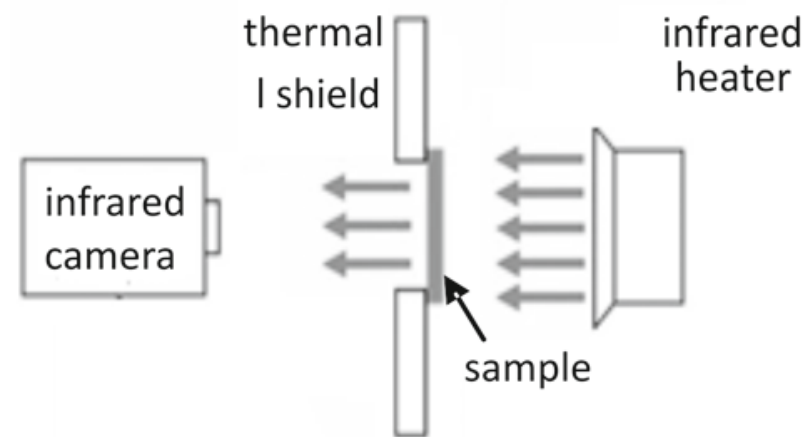

Figure 5. The scheme of the working-station for thermovisual tests of flat samples ${ }^{24}$

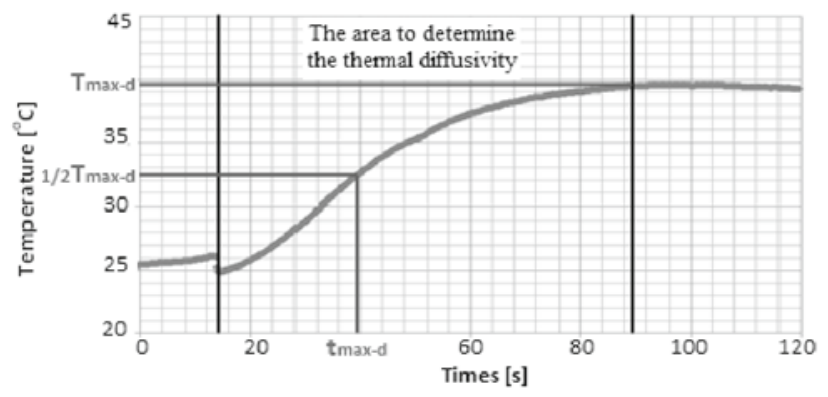

Figure 6. Dependence of temperature of the registration time for a selected flat sample

The analysis of changes in thermal properties of the number of cycles performed on the basis of the determined thermal diffusivity according to the method of Parker ${ }^{3}$ according to the formula:

$d_{c}=1.38 \cdot \frac{g^{2}}{\pi^{2} \cdot t_{\frac{1}{2}}}$

where: $d_{c}-$ thermal diffusivity $\left[\mathrm{mm}^{2} / \mathrm{s}\right], \mathrm{g}-$ thickness of the sample, $t_{1 / 2}-$ the time required to reach half maximum temperature increase.

In order to determine the diagnostic relations it was necessary to conduct the flexural strength examination in compliance with the procedure described in the norm PN-EN ISO $178^{25}$ on the machine Zwick / Roell Z020. The study was conducted on 5 samples cut out along the pipes. Three-point flexural test was conducted at a rate of $5 \mathrm{~mm} / \mathrm{min}$ the flexural strength and modulus were determined.

Additionally, the microscopic tests were conducted, which confirmed the structural changes during the process of fatigue-ageing degradation. These tests were performed with the use of scanning microscope Zeiss 
Supra 25. The samples for the microscopic observation cut out of the glass-polyester pipes were ground and then covered with the gold dust layer.

\section{RESULTS AND DISCUSSION}

The results of thermovisual tests are thermograms (Fig. 7) of the distribution of temperature on the surface of a pipe, showing the changes in the material structure, which are seen during the two-phased process of the heat transition in the radial direction of a pipe.These are the phases of surface heating with halogen radiators and the heat transition after switching off the source of the thermal impulse. These thermograms were used for identification of the material state and determining the diagnostics characteristics - the rates of heating and cooling in compliance with the procedure described in chapter 2, formulas 1-3. The significant advantage of thermovision diagnostics is the possibility of observation and localization of defects at depth, which may be observed on the registered thermograms. The higher is a defect placed under the surface, the higher is the heating temperature. Such relation was confirmed by the research concerning sectional structure of the pipe's wall.

Shown in Figure 8 and 9 examples thermograms recorded during operation of the thermal impulse and after switching off, refer to a pipe working under maximum pressure of $7 \mathrm{MPa}$ and a $110 \times 10^{3}$ cycles. As can be seen in Figure 8 in the selected area are shown subsurface defects resulting from improper supersaturation external protective glass mat. The area, and actually point A has a higher temperature, as can be seen during the heating phase.

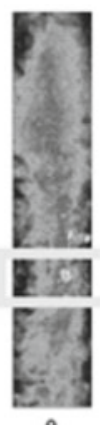

0

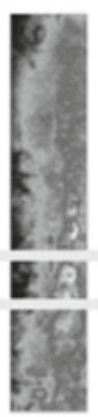

10
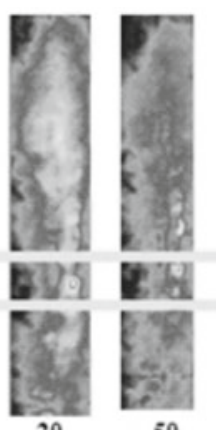

$$
\begin{array}{rr}
50 & 70 \\
\mathbf{x} 10^{3} & \text { cycles }
\end{array}
$$

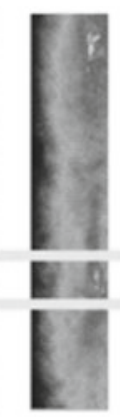

90

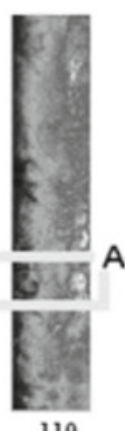

110
Figure 7. Thermograms depending on the number of cycles for a pipe working under the maximum pressure of $7 \mathrm{MPa}$ for a selected creating pipe during the heating process

However, for determining the material condition during the process of fatigue-ageing degradation, more credible are the characteristics determined for the heat flow that occurs during the cooling process. These are the changes observed inside the composite material - Figure 8 .

On the basis of the tests conducted we establish the relationships between of changes in the heating and cooling rates and the number of cycle and the state of the material, which is shown in Figures 9 and 10.

As can be seen, the cooling rate is higher than the rate of heating in the condition of the experiment - Figure 9. The presented characteristics refer to a pipe in which during the ageing-fatigue test were not observed

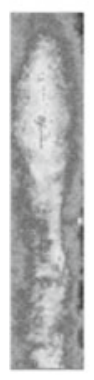

0

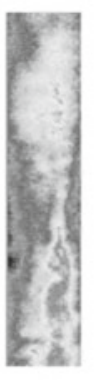

10

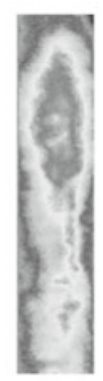

20

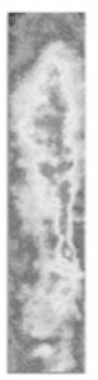

50

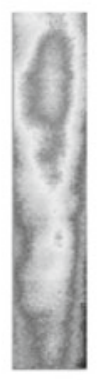

70

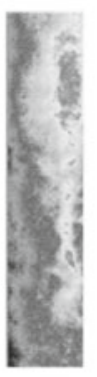

90

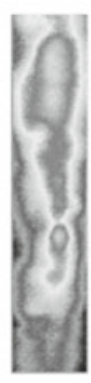

110
Figure 8. Thermograms depending on the number of cycles for a pipe working under the maximum pressure of $7 \mathrm{MPa}$ for a selected creating pipe during the cooling process

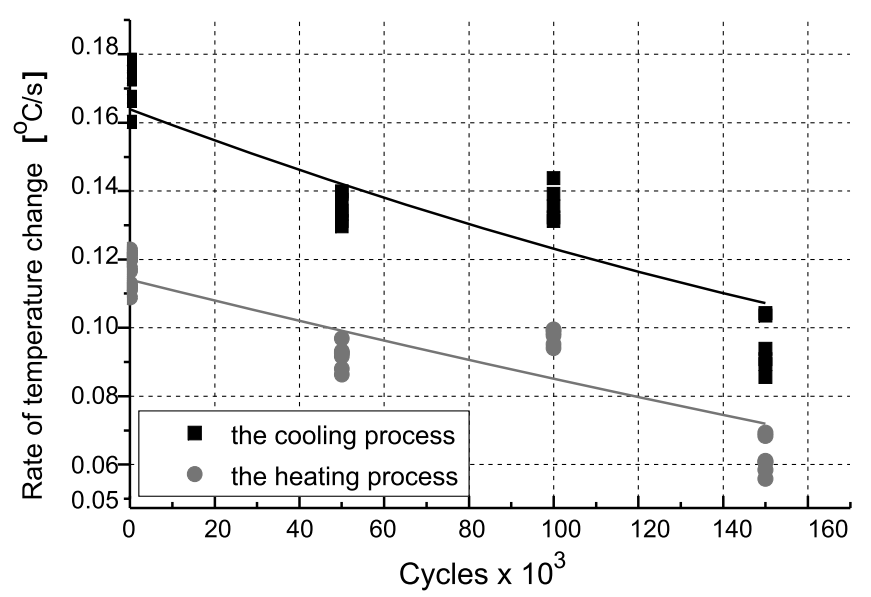

Figure 9. Relationship between the changes in heating and cooling rates and the number of cycles

the so-called "sweating" or surface macroscopic cracks. Therefore, so it can be assumed that the observed changes are the result of microcracks eventually leading to delamination. In case of occurrence delamination, the curves concerning the course of rate in which temperature changes in the crack areas both during the heating and cooling, have a different character than in case of the defects on the micro level. The dependence shown in Figure 10 is characterized by the decrease in the heating and cooling rate, which is the process reflecting the defects in the micro-dimension, and then the increase in rate be observed. It could be interpreted as a delamination process initiation index, which progress is connected with the increase of thermal resistance of the delamination system.

On the basis of non-destructive thermovisual tests conducted, we determined the characteristics of changes in heating and cooling rates in relation to the number of cycles, which are shown in Figure 11. These characteristics are determined for the pipes in which only microscopic defects were observed.

For compare and verify the results were cut out the flat samples in the middle area of pipes. Next were carried out thermal diffusivity tests according to the procedure described in sub chapter 2, formula 4 . The results are presented in Figure 12.

As can be seen in Figure 12, thermal diffusivity of the glass-polyester composites decreases with the number of fatigue cycles. The nature of these changes is similar to the curves presented in Figure 11. However, the change 


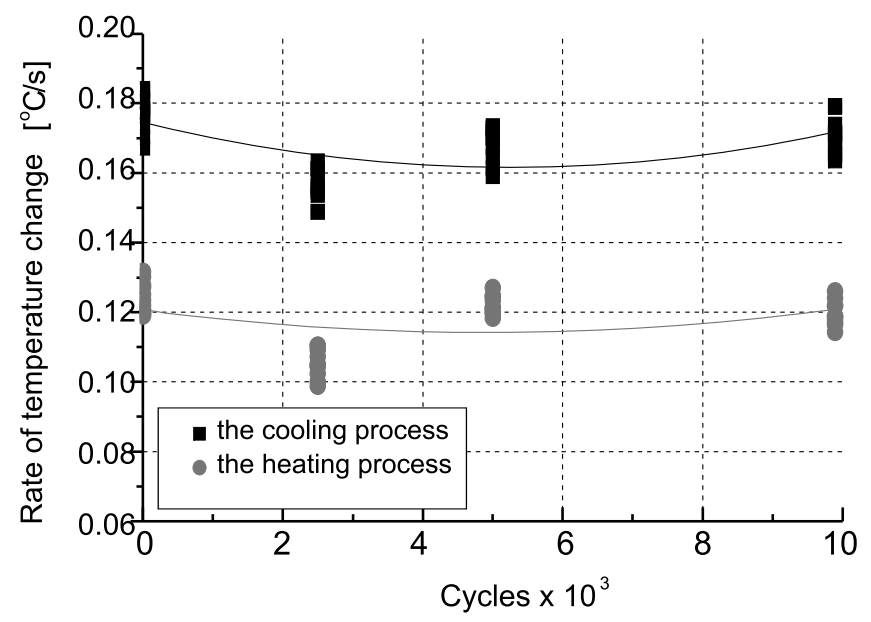

Figure 10. Relationship between the changes in heating and cooling rates and the number of cycles for a pipe with distinct crack

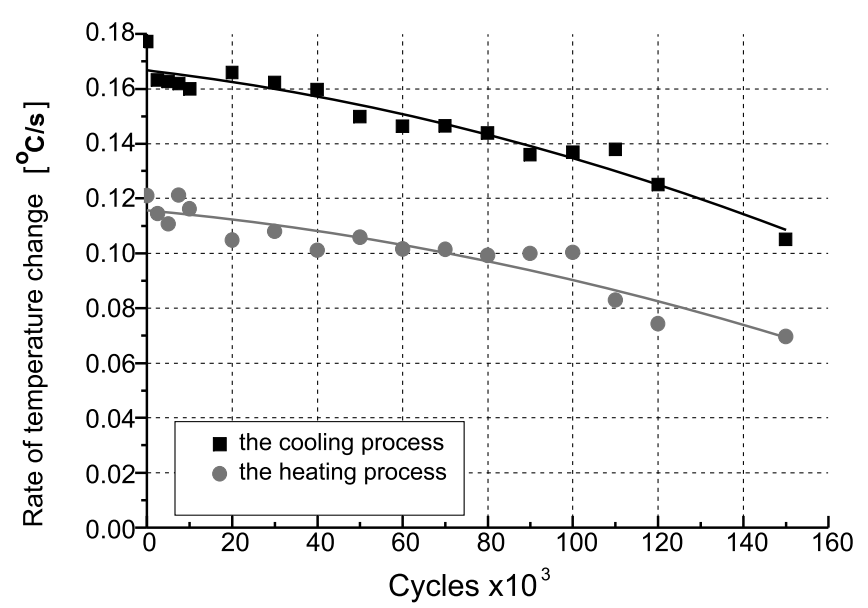

Figure 11. Relationship between the heating and cooling rates and the number of fatigue cycles

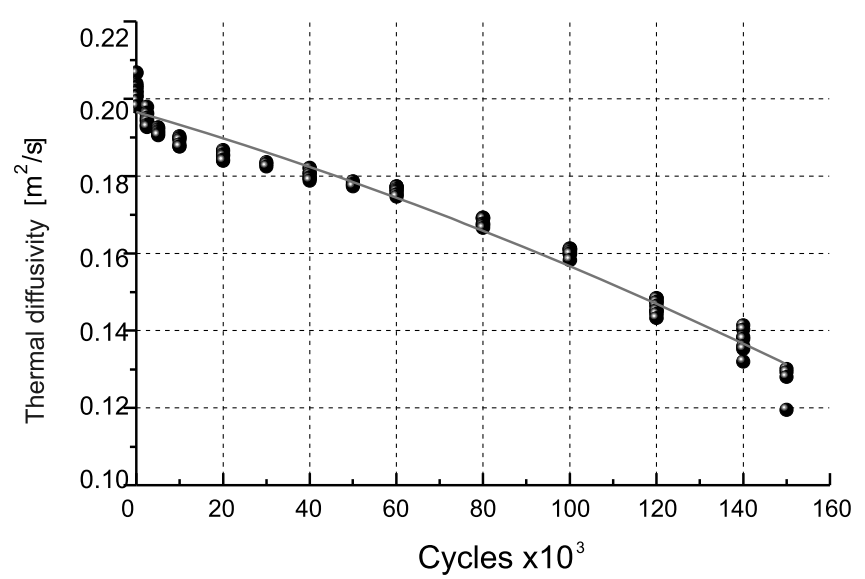

Figure 12. Relationship between the thermal diffusivity and the number of fatigue tests

rate to a greater degree than the thermal diffusivity. Change the heating rate and thermal diffusivity are comparable and are about $70 \%$. Change the heating rate depending on the number of cycles is about $50 \%$.

In order to determine the loss degree of load-bearing properties of glass-polyester composite subjected to thermal and fatigue degradation, the tests were carried out the strength properties during the static flexural test. The results of these tests are presented in Figure 13 flexural strength and Figure 14 - module while flexural.

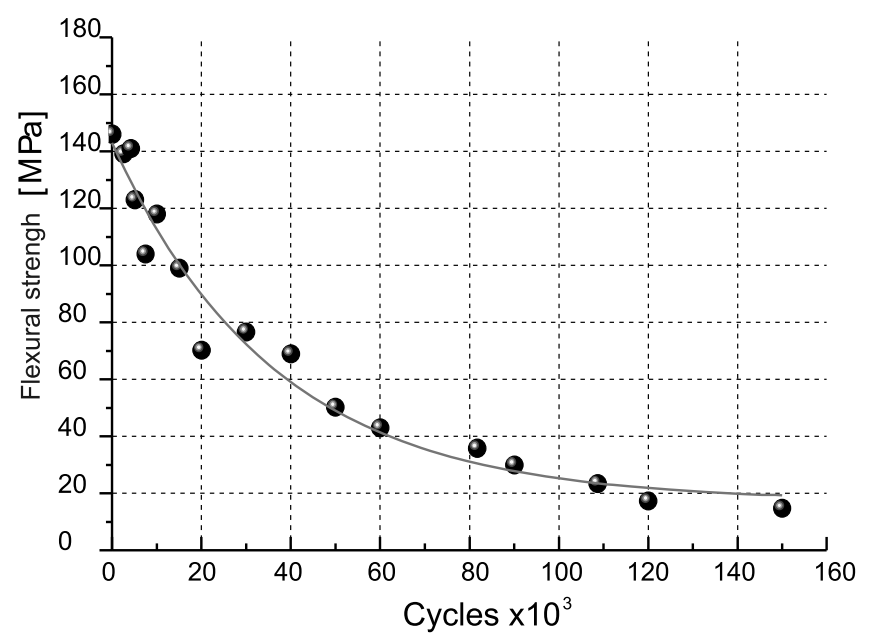

Figure 13. Relationship between the flexural strength and the number of cycles

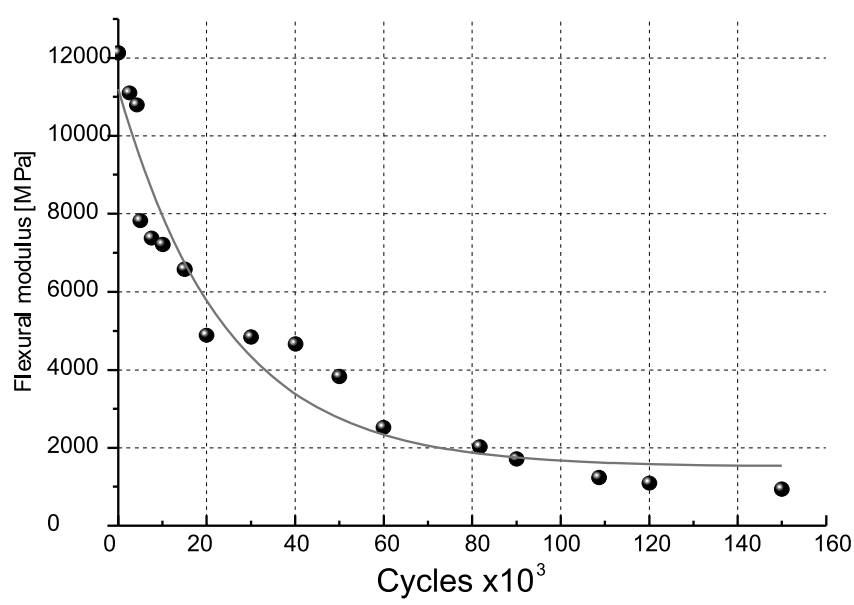

Figure 14. Relationship between the flexural modulus and the number of cycles

As can be seen flexural strength and flexural modulus decreases with the number of cycles of about $85 \%$.

To confirm the changes that occur in the material, the microscopic tests were conducted, the results of which are presented in Table 2.

The views of structural changes in glass-polyester composites in various phases of fatigue-ageing degradation

The view of reference samples, cut out from the pipes which were not subjected to the ageing-fatigue tests with clearly visible deployment of fibres was shown in Tablre $2 \mathrm{a}-\mathrm{b}$. In Table $2 \mathrm{~b}$ we can see a fibres well wetted resin. Table 2c-d show the microscopic photos (after 20000

Table 2. The views of structural changes in glass-polyester composites in various phases of fatigue-ageing degradation

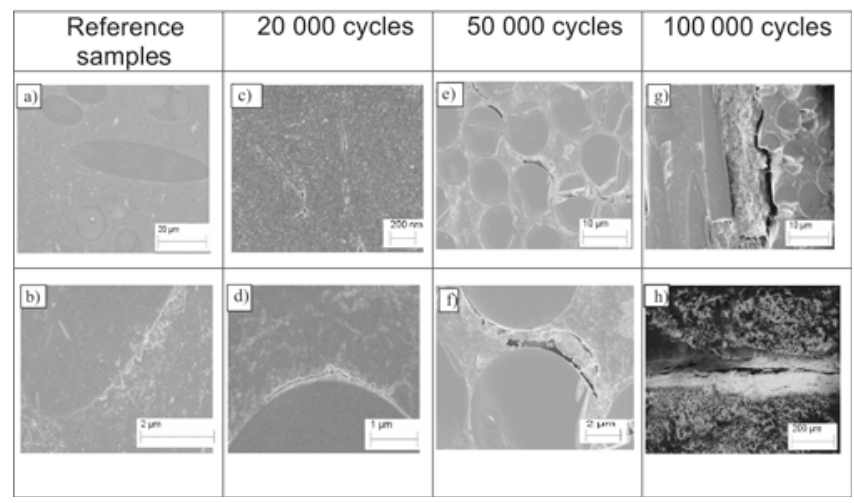


fatigue cycles), in which the first symptoms of discontinuity in the shape of micro destruction such as resin cracks (Table 2c), the adhesion destruction on the border between polyester resin and glass fibres (Table 2d), were observed. The destruction of this sort influenced the decrease in the strength properties and the heating and cooling rates. The images of the changes in the structure after 50000 cycles were presented in Table 2e-f. They are the cohesive cracks, being the effect of micro-cracks propagation leading to delamination - Table $2 \mathrm{~g}-\mathrm{h}$. The defects of this type resulted in premature destruction of the tested composites - loss of tightness, cracking of the pipe. They are the defects at the macro level therefore the researched characteristics for the samples with the destruction of this type were not taken into account for determining the diagnostic relations.

On the basis of the tests, we identified the characteristics between the strength $(\mathrm{Rg})$ and the modulus $(\mathrm{Eg})$ in the condition of flexural with the characteristics of thermal processes - average rate of heating and cooling the composite shell. The relations presented in Figures 15-18, refer to the area, in which delamination did not occur, and the thermal characteristics depending on the number of cycles - Figure 11 (heating and cooling rates) accepted for their construction, correspond to the state of structure of the tested material. This is illustrated the course of changes in the flexural strength (Figure 13)

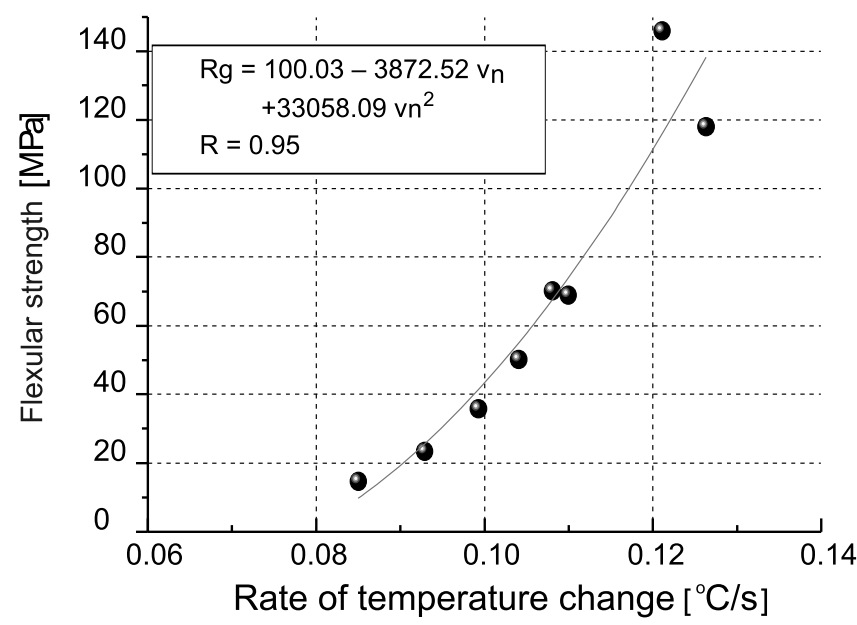

Figure 15. Diagnostic relationship between the flexural strength and the rate of heating temperature change

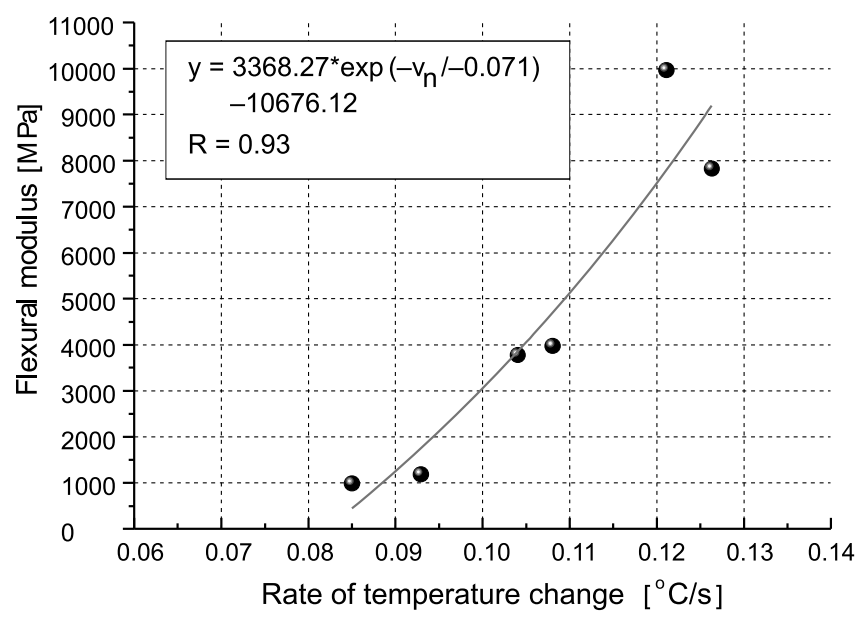

Figure 16. Diagnostic relationship between the flexural modulus and the rate of heating temperature change

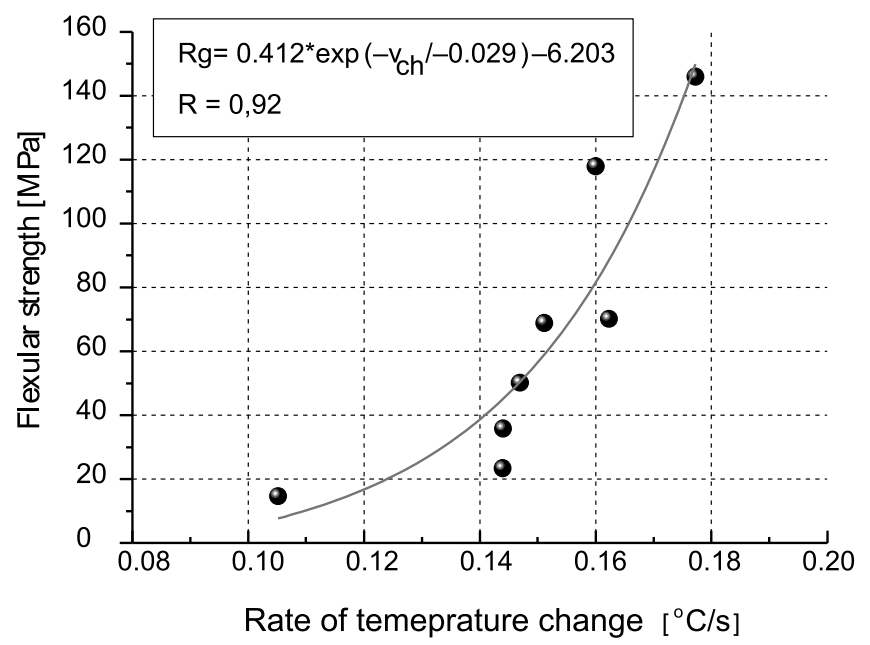

Figure 17. Diagnostic relationship between flexural modulus and the rate of cooling temperature change

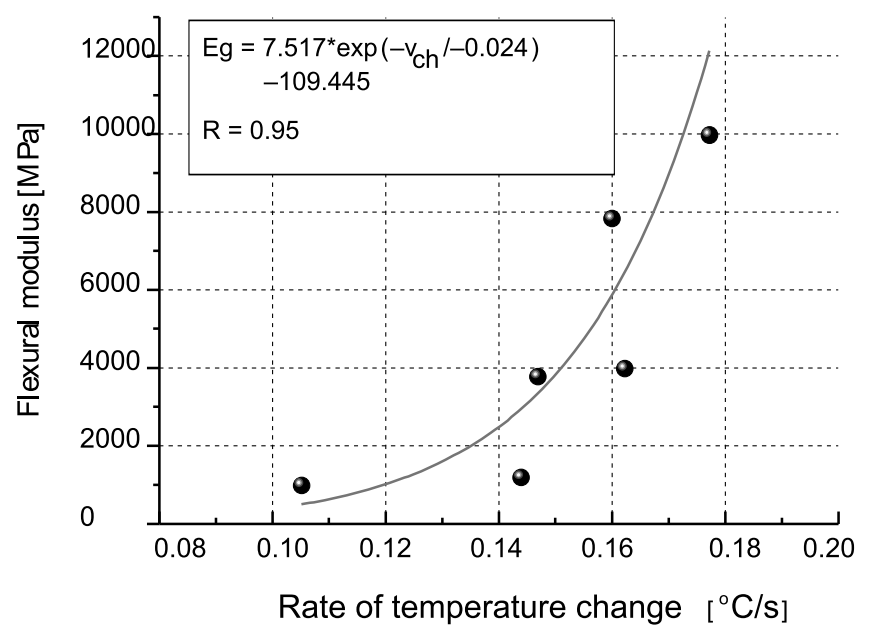

Figure 18. Diagnostic relationship between the flexural modulus and the rate of cooling temperature change

and flexural modulus (Figure 14) during the subsequent phases of the degradation process.

Prepared the diagnostics relationships (Figures 15-18) allow unequivocally define the loss degree of the strength property on the basis of thermal characteristics set with the use of the method of active pulsed thermography. It should be underlined that the most reliable are the relations determined on the basis of flexural strength. Individual features of the relation result from the actual material, geometrical and structural characteristics of the research subject. Therefore, summarized quantities characteristic of the diagnostic relations require individual updating according to the conditions and the subject of the research. Characteristic of the method described is the application of the tool for non-destructive tests, not for the localization of technological macro-defects, or generated in the later phase of the degradation process, but for monitoring the progressive changes in during the exploitation. Thanks to that, we obtain the possibility of the early detection of the areas of the destruction development, volumetric changes of functional properties and comparative assessment of the material quality.

\section{CONCLUSION}

On the basis of the tests conducted, we can conclude that: 
The thermal characteristics i.e. rate of heating and cooling, determined by the method of active pulsed thermography, allow establishing the condition of the material during the exploitation. These rates decrease together with the increase in the number of cycles. Similar changes were observed for thermal diffusivity which confirming the correctness of the adopted method.

The presence of defects shows larger impact on the speed of change in temperature in the phase of cooling rather than heating, which makes the registered thermograms demonstrate more clearly the discontinuity of material in the phase of cooling.

With the increase in the number of fatigue cycles, reflecting the progress of the degradation process of the composites, the strength characteristics are decreasing modulus and flexural strength - flexural modulus (about $90 \%$ ) and flexural strength (about 85\%). This is a result of the changes in the structure of the material. In the first phase, these are cracks of the matrix or debonding on the border of fiber - glass and polyester resin, which lead through the cohesive failure to delamination.

The diagnostics relations, determined with the use of non-destructive thermovisual tests, allow the continuous monitoring of the state of the loss of load-bearing properties of the material from the production stage through assembly and exploitation, up to the early marking of the areas, in which the destruction might occur. It is particularly important from the point of view of work safety and the natural environment. Nevertheless, the relations pertain to the field of research. To broaden the scope, a new research would be required.

\section{LITERATURE CITED}

1. Świderski, W. (2003). Lock-in thermography to rapid evaluation of destruction area in composite materials used in military applications. Proc. SPIE 5132, Sixth International Conference on Quality Control by Artificial Vision, 506. DOI: 10.1117/12.515159.

2. Kaduna, A. \& Gnatowski, A. (2012). Influence of heating rate on evolution of dynamic properties of polymeric laminates. Plast. Rubber Compos. 41(6), 233-239. dx.doi.org/10.1179/174 $3289811 \mathrm{Y} .0000000037$.

3. Avdelidis, N.P., Hawtin, B.C. \& Almond, D.P. (2003). Transient thermography in the assessment of defects of aircraft composites. NDT and E Int. Vol. 36, 433-439. dx.doi. org/10.1016/S0963-8695(03)00052-5.

4. Avdelidis, N.P., Ibarra-Castanedo, C., Maldague, X., MarioliRiga, Z.P. \& Almond, D.P. (2004). A thermographic comparison study for the assessment of composite patches. Infrared Phys. Technol. Vol. 45, 291-299. DOI: 10.1117/12.771082.

5. Bates, D., Smith, G., Lu, D. \& Hewitt, J. (2000). Rapid thermal non-destructive testing of aircraft components. Composites: Part B Vol. 31, 175-185. DOI: 10.1016/S1359-8368(00)00005-6 . 6. Maldague, X.P.V. (2007). Non-destructive evaluation of materials by infrared thermography. London. United Kingdom. Springer-Verlag.

7. Ruddock, R.W. (2013). Basic infrared thermography principles. USA: Reliabilityweb.com

8. Vollmer, M. \& Mollmann, K.P. (2010). Infrared Thermal imaging. Fundamentals, Research and Application. Weinheim, Germany: Wiley-VCH Verlag GmbH\&Co.

9. Rojek, M., Szymiczek, M. \& Wróbel, G. (2011). Nondestructive methods of research on polymer materials. Plastic Process. 6(144), 507-510 (in Polish).

10. Martin, R. (2008). Ageing of composites, Cambridge, England: Woodhead Publishing Limited.
11. Bogdan-Włodek, A., Kozioł, M. \& Myalski, J. (April, 2012). Influence of surface treatment on the wetting process of jute fibres with thermosetting polyester resin. Pol. J. Chem. Technol. 14(1), 21-27. DOI: 10.2478/v10026-012-0054-9.

12. Landowski, M., Budzik, M. \& Imielińska, K. (March, 2011). On degradation of glass/polyester laminate immersed in water. Adv. Mater. Sci. 11(1), 35-39. DOI: 10.2478/v10077-011-004-x. 13. Harris, B. (2003). Fatigue in composites, Cambridge, England: Woodhead Publishing Limited.

14. Rojek, M. (2011). Methodology of diagnostics research of layered composite materials with polymer warp. Gliwice, Poland: International OCSCO World Press (in Polish).

15. Błażejewski, W. (2009). Methodology of selection of the structure of composite braid carriers with reference to containers made by the winding method. Tech. Trans. Mech. 1-M, 9-14. (in Polish).

16. Cohen, D. (1997, July). Influence of filament winding parameters on composite vessel quality and strength. Comp.: Part A, 28A, 1035-1047. DOI: 10.1016/S1359-835X(97)00073-0. 17. Szymiczek, M., Rojek, M. \& Wróbel, G. (2011). Test of composite pipe in the aspect of diagnostic of aging - fatigue changes. Proc. Int. Sem. Sci. Educ. 16-23 April 2011 (61-63). Rome, Italy.

18. Stabik, J., Szymiczek, M., Wróbel, G. \& Rojek, M. (2012). New stand for composite pipes testing. Proceedings of X International Conference of the Quality. Reliability and Long Usage of Technical Systems and Technological Processes. 20-27 November 2012 (63-66). Eilat, Israel.

19. Standards Association of Poland. (2002). Poland standard: Advanced technical ceramics - Monolithic ceramics - Thermo-physical properties - Part 2: Determination of thermal diffusivity by the laser flash (or heat pulse) method. PN-EN 821-2:2002.

20. N501 029 32/2474 - Non-destructive method of assessment concerning the degree of thermal and fatigue degradation of construction polymer composites.

21. Standards Association of Poland. (1993). Poland standard: Plastics - Determination of flexural properties. PN-EN ISO 178-1993. 